\section{Erratum}

https://doi.org/10.11646/zootaxa.5048.4.9

http://zoobank.org/urn:lsid:zoobank.org:pub:710C5782-E57D-4B58-936F-963C80CD80C1

\title{
GERALD F. SHIELDS (2021) Cytogenetics of the Simulium arcticum complex (Diptera: Simuliidae). Zootaxa, 5039: 395-408.
}

On page 400, the following result was omitted:

IIL-9-(Shields et al. 2007). This inversion is male-linked and has its proximal breakpoint in section 56 of the IIL arm and its distal breakpoint in the middle of section 58 of the same arm (Fig. 2). S. arcticum IIL-9 has the largest geographic distribution of all cytotypes of the complex thus far studied. It has been found at 25 locations that encompass 80,000 sq. km. of Western Montana, Central Idaho and Eastern Washington (Shields and Procunier, 2019). IIL-9 was first discovered at Rock Creek, Montana where it existed as $36.5 \%$ of all males. It is most abundant (98.4\% of males) at the Spokane River in Washington state and occurs at all 11 sites at which the cytotype $S$. arcticum IIL-19 is present (see below), suggesting a close relationship between the two. While it is reproductively isolated from the sibling, S. negativum, at the Blackfoot River, Montana, it is not reproductively isolated from the cytotype, IIL-19, at Rock Creek, Montana (Shields et al. 2007). 